\title{
Contração ou expansão? Posicionamentos em pareceres de revista cientifica sob a perspectiva sistemico-funcional
}

\author{
Contraction or expansion? Position in scientific journal peer reviews \\ in the systemic-functional perspective \\ Osilene Maria de Sá e Silva da Cruz \\ Instituto Nacional de Educação de Surdos
}

Resumo: Esta pesquisa analisa pareceres de artigos de uma revista científica de Linguística, com base na perspectiva Sistêmico-Funcional (HALLIDAY, 1985, 1994; HALLIDAY e MATTHIESSEN, 2004) e no Subsistema Engajamento, do Sistema de Avaliatividade (MARTIN; WHITE, 2005). O corpus é constituído por 67 pareceres de artigo: aprovados sem restrições (A), aprovados com restrições (AR) e reprovados (R). Foram identificados treze tópicos (aboutness) abordados pelos pareceristas: Análise, Argumentação, Bibliografia, Contribuição, Forma, Língua, Metodologia, Objetivo, Resultado, Resumo, Tema, Teoria e Título. Os resultados revelam predomínio de posicionamentos heteroglóssicos nos três grupos de pareceres, com um índice maior de posicionamentos monoglóssicos no grupo de pareceres A. O grupo de pareceres AR apresenta mais ocorrências de Expansão Dialógica, sobretudo por significados típicos da categoria Acolhimento. $\mathrm{O}$ grupo de pareceres $\mathrm{R}$ apresenta maior frequência de Contração Dialógica, predominantemente por recursos da categoria Negação.

Palavras-chave: Linguística Sistêmico-Funcional. Avaliatividade. Subsistema Engajamento. Pareceres. Gêneros textuais.

Abstract: This paper analyses peer reviews in one Linguistics scientific journal and is based on the Systemic Functional Linguistics approach (HALLIDAY, 1985; 1994; HALLIDAY; MATTHIESSEN, 2004) and Appraisal System (MARTIN; WHITE, 2005). The corpus consists 
Osilene Maria

de Sá e Silva

dacruz of 67 peer reviews: approved articles without restrictions (A), approved articles with restrictions (AR) and rejected articles (R). The study identified thirteen topics (aboutness) discussed by referees: Abstract, Analysis, Argumentation, Bibliography, Contribution, Form, Language, Methodology, Objective, Result, Theme, Theory and Title. Results reveal a predominance of heteroglossia in all the three groups, although more instantiations of monoglossicpositionings in group A was observed. Group AR presents frequent occurrences of Dialogic Expansion through meanings of Entertain. Group R presents more frequency of Dialogic Contraction, predominantly through resources of Negation.

Key words: Systemic Functional Linguistics. Appraisal.Engagement subsystem. Peer reviews. Textual genres.

\section{Introdução}

"Publique ou pereça" . A célebre citação, cuja autoria é atribuída a diversas fontes, faz parte de uma cultura cada vez mais arraigada na comunidade científica nacional e internacional, levando a comunidade acadêmica a publicar em grande escala. Tendo em vista a importância da publicação científica no mundo atual e seu papel na divulgação de trabalhos de qualidade e referência, esta pesquisa, recorte de um trabalho mais amplo sobre avaliação de artigos submetidos para publicação, busca analisar o modo como os pareceristas se posicionam ao elaborar a avaliação.

A avaliação, tradicionalmente denominada parecer, é definida como "uma opinião de um especialista em resposta a uma consulta" (HOUAISS; VILLAR, 2001, p. 2.133) e possibilita a legitimação do trabalho acadêmico e a veiculação do conhecimento de forma confiável. Sendo assim, o parecer tem grande importância na academia porque apresenta o aval do parecerista acerca de determinado trabalho, trazendo críticas positivas e/ou negativas referentes a componentes de um artigo acadêmico, seja à parte formal (estrutura do trabalho e linguagem), à parte conceitual (teoria(s) envolvida(s) na pesquisa) e/ou à parte metodológica (procedimentos realizados na pesquisa).

Um levantamento bibliográfico detalhado revelou que o estudo do gênero parecer de artigo de revista científica não tem sido alvo da área da

\footnotetext{
1. De acordo com o site Wikipédia, as primeiras ocorrências dessa citação em inglês - "Publish or perish" - datam de 1932, 1938 e 1942. A primeira ocorreu em um contexto não acadêmico, no livro Archibald Cary Coolidge: life and letters, de Harold Jefferson Coolidge; a segunda, em um contexto acadêmico, no vol. 24 da obra Association of American Colleges Bulletin; e a terceira, no livro The academic man: a study in the Sociology of a profession. Disponível em: <en.wikipedia.org/wiki/Publish_or_perish>. Acesso em: 30 abr. 2011.
} 
Linguística, em especial, da LSF e do Sistema de Avaliatividade, áreas de interesse desta pesquisa. Podem-se citar, embora sem vínculo com a LSF, poucos trabalhos sobre o mesmo tema no cenário de pesquisas, tais como a de Ramos-Álvarez et al. (2008) sobre a descrição de critérios de pareceristas ao analisarem textos acadêmicos na área de Psicologia; e a elaborada por Beserra (2006) e inserida no campo teórico da sociorretórica de Bazerman (1994; 2006) e Miller (1994), que mostra as diferenças linguísticas e formais em pareceres médicos e pareceres pedagógicos, relacionadas ao contexto cultural e situacional de cada área de conhecimento.

$\mathrm{Na}$ próxima seção, apresento o arcabouço teórico-metodológico fundante deste trabalho, trazendo uma síntese sobre a Linguística Sistêmico-Funcional e sobre o subsistema Engajamento, componente do Sistema de Avaliatividade.

Contração ou expansão? posicionamentos em pareceres de revista científica sob a perspectiva sistemicofuncional

\section{A Linguística Sistêmico-Funcional}

A LSF (HALLIDAY, 1994; HALLIDAY; MATTHIESSEN, 2004), leva em consideração as escolhas em termos de significados e os contextos em que essas escolhas estão inseridas: de situação (léxico-gramática) e de cultura (padrões organizacionais e sociais), uma vez que a linguagem, para a teoria, é vista como um fenômeno atrelado às funções sociais e aos contextos sociais. Essas características possibilitam a investigação proposta nesta pesquisa, pois o parecer de artigo de revista científica é um texto específico, elaborado por avaliadores inseridos em uma comunidade discursiva também específica, com padrões particulares de elaboração (léxico-gramaticais e semânticos) dentro dos contextos nos quais foram elaborados e circulam.

Halliday (1994) propõe que a linguagem traduz significados por meio de três metafunções: ideacional (campo), interpessoal (relações entre os interlocutores) e textual (modo de apresentação de um texto/enunciado). Neste trabalho, o enfoque será dado à metafunção interpessoal, sintetizada a seguir, porque a análise dos pareceres mostra a relação entre parecerista e autor do artigo submetido para publicação. Além disso, pela análise do subsistema Engajamento, é possivel verificar o posicionamento dos pareceristas ao apresentarem as avaliações dos artigos analisados.

\subsection{A metafunção interpessoal}

A metafunção interpessoal evidencia as relações entre os participantes do discurso e sua interação, na qual o falante assume um papel de fala e demanda do seu ouvinte uma resposta. Halliday (1994, p. 68) 
Osilene Maria

de Sá e Silva

dacruz

indica que, ao proferir um enunciado, "o falante adota para si um papel particular no discurso e, dessa forma, atribui ao ouvinte um papel complementar que ele quer que este adote" ${ }^{2}$. Ocorrem, então, situações comunicativas distintas, como um pedido, um convite, uma avaliação, uma rejeição, dentre outras, que são realizadas na interação entre os falantes, ou uma troca, na qual "dar" implica "receber" e "pedir" implica "dar". Nesse contexto, os interlocutores desempenham os principais papéis de fala: dar e pedir, nos quais estão incluídos todos os outros papéis (HALLIDAY, 1994, p. 68; HALLIDAY; MATHIESSEN, 2004, p. 107). Essa relação implica uma troca ("commodity") de bens e serviços ou de informações. A função semântica da oração como troca de bens e serviços é denominada proposta e função semântica da oração como troca de informações é denominada proposição (HALLIDAY, 1994, p. 89).

Nos pareceres analisados, é possível identificar as relações entre os participantes, pois o parecerista, ao apresentar sua crítica, pede ou dá informações, e é por meio de escolhas léxico-gramaticais que expõem seus pontos de vista, revelando aspectos relacionados a poder, status, afeto, julgamento em relação a outros interlocutores, assim como a negociação e busca de solidariedade para que suas ideias sejam compreendidas e aceitas.

Dando sequência ao pressuposto teórico-metodológico adotado nesta pesquisa, a seguir, apresento o subsistema de Engajamento, parte do Sistema de Avaliatividade (MARTIN; WHITE, 2005), calcado no arcabouço da metafunção interpessoal.

\section{0 sistema de Avaliatividade e o subsistema Engajamento} Nesta pesquisa, adoto o Sistema de Avaliatividade, consubstanciado em Martin e White (2005), porque se enquadra no escopo da LSF, especificamente, do significado interpessoal, atrelado às relações sociais escritor e leitor (parecerista e articulista).

Para Martin e White (2005), o Sistema de Avaliatividade está em consonância com a Gramática Sistêmico-Funcional porque as escolhas lexicais não acontecem por acaso; pelo contrário, são fruto de algumas preferências lexicais em detrimento de outras. Além disso, a LSF analisa a língua em uso, destacando seu aspecto social. Dessa forma, o Sistema

\footnotetext{
2. Todas as traduções do inglês para o português foram realizadas pela autora.
} 
de Avaliatividade possibilita ao pesquisador analisar aspectos de avaliação presentes no discurso, produzido dentro de uma esfera social, formada por valores, contextos culturais e sociais.

Martin e White (2005) destacam que o significado interpessoal da linguagem é construído no discurso, principalmente, pela variável relações, uma vez que nela ocorrem a crítica (positiva ou negativa) e a negociação sobre determinado assunto. Dessa forma, o Sistema de Avaliatividade encontra subsídios para a análise dos elementos avaliativos do discurso no estrato léxico-gramatical, especificamente na variável relações. Martin e White $(2005$, p. 29) recorrem à definição da variável relações proposta por Halliday (1985), destacando a função dos participantes, os respectivos status e os papéis na interação.

Analogamente ao que é feito pela LSF, o foco do estudo do SisContração ou expansão? posicionamentos em pareceres de revista científica sob a perspectiva sistemicofuncional tema de Avaliatividade é centrado em interações verbais ou escritas em determinados contextos socioculturais. Esse sistema é constituído por três Subsistemas: Atitude, mais especificamente nas realizações de Afeto (Emoção), Julgamento (Ética) ou Apreciação (Estética); Engajamento, foco deste trabalho, por meio de posicionamentos monoglóssicos e heteroglóssicos de Contração e Expansão Dialógica; Gradação, subdividido em recursos de Força e Foco, nas ocorrências de amplificação ou mitigação das avaliações.

Apesar de ainda incipientes no Brasil, estudos fundamentados no Sistema de Avaliatividade têm apresentado enfoques distintos e resultados que servem como referência para pesquisadores preocupados em analisar a avaliação em diferentes gêneros. Como exemplos de sistemicistas envolvidos em pesquisas sobre avaliação, especificamente no escopo da Avaliatividade, citamos Cabral (2007), campo semântico Julgamento; Rodrigues Jr. (2008), transitividade e Avaliatividade; Paula (2009), metadiscurso interpessoal e textual; Vian Jr. (2009), Subsistema Gradação; Almeida (2010), recursos atitudinais; Ikeda (2011), campo semântico Julgamento; Sobhie (2011), Subsistema Engajamento e Carvalho (2011), Subsistema Atitude.

Os pressupostos de Bahktin ([1929]1999) inspiraram estudiosos sobre o Sistema de Avaliatividade, sobretudo no que se refere à intertextualidade, uma vez que o filósofo da linguagem considera o significado como parte de um grupo maior em relação a outros significados, representados pela noção de dialogismo e heteroglossia. Dessa forma, a relação entre a avaliação e a intertextualidade se estabelece porque os 
Osilene Maria

de Sá e Silva

dacruz recursos do Sistema de Avaliatividade constroem a intersubjetividade dos falantes/ouvintes ou escritores/leitores e a intertextualidade estabelece a relação entre os textos. Para Bakhtin ([1929]1999, p. 71), toda comunicação verbal - escrita ou falada - é dialógica, porque falar ou escrever é referir-se àquilo que foi dito ou escrito anteriormente e, concomitantemente, antecipar respostas potenciais ou imaginadas pelos leitores ou ouvintes.

A seguir, apresento uma síntese do Subsistema Engajamento, foco deste trabalho.

\subsection{Subsistema Engajamento}

Martin e White (2005, p. 5) destacam que, ao transmitir um enunciado, o falante/escritor convida o ouvinte/leitor a compartilhar suas ideias e posicionamentos, provocando uma situação dialógica (BAKHTIN, [1929]1999), traduzida como interação verbal, na qual pode ocorrer uma resposta a uma proposição anunciada, uma afirmação sobre algo que pode provocar outra resposta e também antecipar possíveis respostas afirmativas ou objeções.

Dentro dessa perspectiva dialógica, os autores descrevem o Subsistema Engajamento em termos de duas posturas possivelmente assumidas pelo produtor em um texto, como mostra o quadro a seguir.

\begin{tabular}{|l|l|}
\hline $\begin{array}{c}\text { Monoglossia } \\
\text { (sem reconhecimento } \\
\text { de alternativa dialógica) }\end{array}$ & \multicolumn{1}{c|}{$\begin{array}{c}\text { Heteroglossia } \\
\text { (com reconhecimento de alternativa dialógica) }\end{array}$} \\
\hline $\begin{array}{l}\text { Os bancos são } \\
\text { gananciosos. }\end{array}$ & $\begin{array}{l}\text { Há um argumento de que os bancos são gananciosos. } \\
\text { Na minha opinião, os bancos são gananciosos. } \\
\text { Não se pode negar que os bancos são gananciosos. } \\
\text { Todos sabem que os bancos são gananciosos. }\end{array}$ \\
\hline
\end{tabular}

Quadro 1 - Monoglossia e heteroglossia (Martin; White, 2005, p. 100; minha trad.)

Os posicionamentos monoglóssicos são definidos como a instância do discurso na qual não há possibilidade de posições alternativas ou dialógicas, pois as declarações são realizadas de forma absoluta, e os posicionamentos heteroglóssicos são caracterizados pelo discurso constituído por posições ou vozes alternativas (MARTIN; WHITE, 2005, p. 99-100).

A realização heteroglóssica concebe um modelo de posicionamento intersubjetivo, que consiste do posicionamento do falante/escritor no discurso, por meio de modalidade, polaridade, intensificação, 
atribuição, concessão e consequência (MARTIN; WHITE, 2005, p. 94). É subdividida em Contração Dialógica (dialogic contraction), quando ocorrem desafios ou restrições em relação a outras vozes ou opiniões, e em Expansão Dialógica (dialogic expansion), quando se permitem vozes ou opiniões dialogicamente alternativas (MARTIN; WHITE, 2005, p. 102). Em outras palavras, a primeira dificulta a possibilidade de abertura do espaço dialógico para outros posicionamentos, ao passo que a segunda proporciona essa possibilidade.

Ao utilizar recursos de Contração Dialógica, o autor/falante assume uma posição de rejeição em relação a um espaço dialógico. Dessa forma, esses recursos transmitem formulações que desafiam, evitam ou restringem posições alternativas. Refutação (Disclaim) e Ratificação (Proclaim) são as subdivisões de Contração Dialógica.

Contração ou expansão? posicionamentos em pareceres de revista científica sob a perspectiva sistemicofuncional autor assume que há uma posição contrária. Para externar essa posição contrária, o autor utiliza dois recursos: Negação (Deny) e Contraexpectativa (Counter).

Negação é o recurso pelo qual a opinião do falante se opõe à voz citada, negando-a, ou mostrando uma opinião contrária à voz autoral. Nessa modalidade, passa-se a impressão de que o autor/falante sabe mais sobre o assunto do que o leitor/ouvinte e age de forma a corrigir algum erro ou mal-entendido por parte do interlocutor (MARTIN; WHITE, 2005, p.118). O exemplo a seguir ilustra esse recurso.

Ex.: Nós todos gostamos de algo para agarrar. Mas às vezes você pode ter muito de uma coisa boa. E um homem cuja dieta consiste de chessburgers duplos e batatas fritas pode acabar parecendo um tubo de banha. Não há nada de errado com carne, pão e batata frita. Mas que tal carne magra, pão integral e batata assada? (MARTIN; WHITE, 2005, p. 118).

Contraexpectativa é o recurso que transmite concessão em relação a uma dada ideia e é realizado tipicamente por meio de conjunções e conectivos (“embora", "entretanto", “ainda", "mas”...), advérbios ("surpreendentemente"...) e adjuntos ("somente", “ainda"...). Mantém-se com o interlocutor uma relação no sentido de criar outra expectativa, como se pode ver no exemplo a seguir. 
Ex.: Apesar de estarmos nos divorciando, Bruce e eu ainda somos bons amigos. (MARTIN; WHITE, 2005, p. 120).

O recurso de Contraexpectativa é muito parecido com o recurso Negação, porque em ambos a avaliação é apresentada e, em seguida, outro significado é revelado. A diferença consiste na realização do significado, uma vez que a Negação é realizada por meio de polaridade negativa, principalmente pela palavra "não" ou itens lexicais de sentido

Osilene Maria de Sá e Silva dacruz negativo, como "nunca", “jamais", dentre outros. Por outro lado, a Contraexpectativa é realizada principalmente por conjunções ("mas", "no entanto", "embora") e por advérbios ("só", “somente”). Em termos de significado, o primeiro denota uma proposição incisiva, com a mínima possibilidade de resposta. 0 segundo, por sua vez, denota uma expectativa do falante/escritor que não foi satisfeita.

Os significados de Ratificação são realizados por meio de três recursos: Confirmação de Expectativa (Concur), Endosso (Endorsement) e Pronunciamento (Pronounce).

Os recursos de Confirmação de Expectativa envolvem enunciados nos quais o autor mostra estar em concordância com alguma proposição apresentada. É dialógico porque apresenta escritor em diálogo com a audiência do texto, e é sinalizado por meio de expressões, como: “é claro", "naturalmente", “certamente", “obviamente" (MARTIN; WHITE, 2005, p. 122).

Ex. Abu Dhabi TV: Por que esses grupos recorrem à violência, Vossa Majestade, apesar da contradição entre violência e Islamismo?

HM King Abdullah: Naturalmente, nós compreendemos o estado de fúria e frustração que árabes e muçulmanos sofrem como resultado de seus sentimentos de ausência de justiça [...]. (MARTIN; WHITE, 2005, p. 122-123).

O recurso Endosso mostra a concordância da voz autoral com vozes externas, as quais são consideradas válidas, incontestáveis, garantidas e corretas. Esse recurso é realizado por meio de processos verbais como "mostrar", “provar", “demonstrar", "achar", “apontar”, para citar alguns. Martin e White (2005, p. 126) destacam que "ao referenciar e endossar uma voz anterior, a voz do autor entra em relação dialógica de alinhamento com o falante". 0 exemplo a seguir ilustra esse recurso. 
Ex.: Cinco dos estudos examinam os efeitos da dependência econômica na desigualdade econômica. Todos os cinco mostram que a dependência está associada à grande desigualdade. Mais especificamente, os cinco estudos demonstram que a dependência de investimento - investimentos de firmas estrangeiras na economia doméstica da sociedade - aumentam a desigualdade econômica. (MARTIN; WHITE, 2005, p. 126).

Nota-se nesse exemplo que o autor reforça seu enunciado por meio dos processos verbais "mostrar" e "demonstrar", enfatizando a sua própria voz e dificultando a argumentação do leitor em relação ao que foi dito anteriormente.

O recurso Pronunciamento abrange enunciados que envolContração ou expansão? posicionamentos em pareceres de revista científica sob a perspectiva sistemicofuncional vem ênfase ou intervenção/interpolação explícita. Ao discordar, o autor se coloca diretamente contra a voz do outro e, ao proclamar, a negação é colocada indiretamente. É realizado por meio de expressões como "Eu afirmo que...", "O fato é que...", "A verdade do problema é que...", "Nós só podemos concluir que...", "Você deve concordar que...", "Realmente...", dentre outros (MARTIN; WHITE, 2005, p. 127). Esses significados expõem mais a subjetividade, como uma estratégia do autor para convencer sua audiência. $O$ exemplo a seguir ilustra esse recurso.

Ex. Está absolutamente claro para mim que o que Charlotte argumentava sobre o filme Crouching Tiger é que ele era ruim na opinião das audiências liberais as quais impunham esse significado em virtude dos próprios preconceitos sobre o cinema chinês e sobre os chineses em geral. (MARTIN; WHITE, 2005, p. 128)

Dando continuidade aos tipos de posicionamentos, a Expansão Dialógica, é realizada por meio de duas categorias: Acolhimento ${ }^{3}$ (Entertain) e Atribuição (Attribute), sendo esta categoria subdividida em Reconhecimento (Acknowledge) e Distanciamento (Distance).

\footnotetext{
3. 0 termo Entertain também tem sido traduzido como Entretenimento. Nesta pesquisa, a opção pelo termo Acolhimento deve-se ao fato de considerar que a tradução Entretenimento não abarca os significados que a palavra carrega neste contexto de pesquisa. No contexto teórico-metodológico desta pesquisa, o termo Acolhimento traduz significado de abertura dialógica ao interlocutor, ou seja, acolhe ou leva em consideração posicionamentos ou opiniões do interlocutor.
} 
Osilene Maria de Sá e Silva

daCruz

A categoria Acolhimento refere-se à voz autoral como uma dentre as vozes existentes no texto, sendo o posicionamento fundamentado na subjetividade do autor. É realizada no discurso por meio de diferentes locuções modalizadoras, como auxiliares modais ("pode", "poderia", "podia", “deve”...), adjuntos modais ("talvez", "provavelmente”, “definitivamente"...), atributos modais ("É possível que...", “É provável que",...), circunstâncias de ângulo ("no meu ponto de vista", ...), processos mentais ("Eu acho", "Eu acredito", ...), perguntas abertas e metáforas interpessoais. $\mathrm{O}$ exemplo a seguir pode ilustrar.

Ex. Este foi, possivelmente, o discurso mais imaturo, irresponsável, vergonhoso e enganoso que um Primeiro Ministro Britânico já proferiu. (MARTIN; WHITE, 2005, p. 106)

Martin e White (2005, p. 105) destacam que a categoria Acolhimento abrange construções mais polidas, de modo que o autor/falante se posiciona, mas se protege ao amenizar o enunciado. Thompson (1996, p. 59-63), apoiado nos pressupostos sistêmico-funcionais, já considerava que, ao expressar sua atitude em relação a algo ou alguém, o falante pode assumir a responsabilidade e seu comprometimento em relação àquele enunciado, e que ambos podem ser expostos de forma explícita ou implícita, dependendo do objetivo do falante. $O$ autor reitera o pressuposto de que a modalidade é um dos elementos que sinalizam a responsabilidade e o comprometimento do falante na elocução.

A categoria Atribuição refere-se à indicação de uma voz externa no texto, que pode estar identificada explícita ou implicitamente no discurso, de modo a interagir com o interlocutor ou se distanciar dele (MARTIN; WHITE, 2005, p. 111). A realização dessa categoria ocorre por meio de verbos sinalizadores de discurso direto e indireto ("dizer", "relatar", dentre outros), verbos que indicam processos mentais ("acreditar", “crer", "pensar”, dentre outros) ou nominalização.

A categoria Atribuição é subdividida em duas subcategorias: Reconhecimento (Acknowledgement) e Distanciamento (Distance), ambas heteroglóssicas, uma vez que o autor /falante evita se posicionar, trazendo, portanto, outra voz para seu texto.

A subcategoria Reconhecimento possibilita dissociar a voz autoral da proposição em ação, ou seja, possibilita ao produtor do texto não expressar seu posicionamento explicitamente, fazendo isso por meio da 
voz do outro. Os significados dessa subcategoria são dialógicos, porque separam a voz do autor/ falante da voz de outro interlocutor. Conforme Martin e White (2005, p. 112-113), isso não significa que o autor /falante se distancie do texto totalmente, mas o faz especificamente naquele ponto. Os autores destacam a incidência dessa subcategoria no discurso acadêmico no uso de citações. $O$ exemplo a seguir ilustra uma ocorrência dessa subcategoria.

Ex. Tikner disse que independente do resultado, a comissão Royal foi uma perda de dinheiro e ele iria fazer uma investigação separada sobre a questão feita por Jane Matheews. [...]. (MARTIN; WHITE, 2005, p.113).

Contração ou expansão? posicionamentos em pareceres de revista científica sob a perspectiva sistemicofuncional

A subcategoria Distanciamento denota o afastamento explícito da voz autoral no texto. $O$ autor do enunciado expressa clara e explicitamente seu distanciamento do enunciado. 0 processo utilizado como exemplo nessa subcategoria é o processo claim ("afirmar", "reivindicar", "alegar, e outros), em que a voz do autor está separada, de modo que ele se isenta totalmente da responsabilidade daquilo que está sendo afirmado.

Ex. $O$ ataque dele ocorreu quando a mulher aborígene envolvida no caso pediu a uma ministra para examinar as crenças religiosas que elas argumentam serem inerentes na sua luta contra a construção de uma ponte para a ilha próxima a Goolwa no sul da Austrália. (MARTIN; WHITE, 2005, p. 113).

Apresentado o escopo teórico desta pesquisa, apresento, a seguir, os procedimentos metodológicos do trabalho.

\section{Metodologia da pesquisa}

Neste trabalho, adoto a abordagem de pesquisa qualitativa (CHIZZOTTI, 1998; DENZIN; LINCOLN, 1998; MOITA LOPES, 2001; DUFF, 2002; FLICK, 2009, dentre outros), adaptando os procedimentos metodológicos de Martin e White (2005, p. 69-261). Justifico a opção, neste estudo, pela abordagem de pesquisa qualitativa devido ao foco principal da pesquisa: análise de conteúdo, mais especificamente, análise dos discursos referentes aos posicionamentos dos pareceristas no corpus de estudo. 


\subsection{0 corpus da pesquisa}

O quadro a seguir apresenta as principais características do corpus analisado.

Osilene Maria

de Sá e Silva

daCruz

\begin{tabular}{|l|l|l|}
\hline \multicolumn{2}{|c|}{ Características do corpus } \\
\hline Área de conhecimento & \multicolumn{1}{|l|}{ Linguística } \\
\hline Classificação CAPES & A1 \\
\hline \multirow{3}{*}{ No de pareceres } & & 12 Aprovados \\
\cline { 2 - 3 } & 67 & 35 Aprovados com restrições \\
\cline { 2 - 3 } Total de palavras & 34.707 \\
\hline Idioma & Português brasileiro \\
\hline Período de produção & $2004-2010$ \\
\hline
\end{tabular}

Quadro 2 - Características do corpus da pesquisa

\subsection{Descrição e organização do corpus}

Antes de realizar a análise dos pareceres, foram seguidos alguns procedimentos:

1) Conferência e agrupamento dos pareceres em três blocos: pareceres aprovados sem restrições (A), pareceres aprovados com restrições (AR) e pareceres reprovados (R).

2) Codificação e numeração dos pareceres:

- 12 pareceres aprovados sem restrições (A): de 01 a 12 - A01, A02, A03, A04 até A12;

- 35 pareceres aprovados com restrições (AR): de 01 a 35 - AR01, AR02, AR03, AR04 até AR35;

- 20 pareceres reprovados (R): de 01 a 20 - R01, R02, R03, R04 até R20.

3) Identificação dos tópicos (aboutness) abordados pelos pareceristas: análise, argumentação, bibliografia, contribuição, forma, língua, metodologia, objetivo, resultado, resumo/abstract, teoria, tema, título ${ }^{4}$.

4) Identificação das escolhas léxico-gramaticais sinalizadoras de Engajamento ${ }^{5}$, a partir da proposta metodológica de Martin e White (2005, p.69-261).

\footnotetext{
4. Neste trabalho, não será possível a apresentação de cada tópico por uma questão de delimitação de espaço.

5. Como informado anteriormente, esta pesquisa é um recorte de um estudo mais amplo, no qual foram analisados também os Subsistemas Atitude e Gradação. Como o foco do artigo é a apresentação do posicionamento dos pareceristas, o enfoque será para o subsistema Engajamento.
} 
Na próxima seção, apresento a análise e a discussão dos dados obtidos.

\section{Análise e discussão dos dados}

Esta seção procura analisar o posicionamento dos pareceristas ao apresentarem suas avaliações (críticas, sugestões ou recomendações). Para isso, retomo uma questão premente para Martin e White (2005), ao proporem que os enunciados de um falante/escritor sinalizam seu posicionamento no discurso, mostrando o tipo de relação/interação mantida com o interlocutor. Esses enunciados são realizados de forma monoglóssica (monoglossic ou undialogised), quando não possibilitam interação entre escritor/falante e leitor/ouvinte, portanto, sem referências a outras vozes ou pontos de vista, ou heteroglóssicas (heteroglossic ou dialoContração ou expansão?

posicionamentos em pareceres de revista científica sob a perspectiva sistemicofuncional gised), cuja abertura para a interação entre os participantes do discurso invoca ou permite alternativas dialógicas, de expansão ou de contração (MARTIN; WHITE, 2005, p.99-100).

Apresento, a seguir, o quadro 3 com o quantitativo de posicionamentos monoglóssicos e heteroglóssicos ${ }^{6}$. Os dados serão apresentados e discutidos separadamente, por grupo de pareceres.

\begin{tabular}{|c|c|c|c|}
\hline \multicolumn{4}{|c|}{ Quantitativo de posicionamentos nos pareceres } \\
\hline $\begin{array}{l}\text { Grupo de } \\
\text { pareceres }\end{array}$ & $\begin{array}{c}\text { Monoglós- } \\
\text { sicos }\end{array}$ & & $\begin{array}{c}\text { Heteroglóssicos } \\
\text { (categorias predominantes) }\end{array}$ \\
\hline \multirow{2}{*}{$\begin{array}{l}\text { A } \\
\text { (12 pareceres) }\end{array}$} & \multirow{2}{*}{$59(42 \%)$} & \multirow{2}{*}{$79(58 \%)$} & $\begin{array}{l}\text { Contração Dialógica (41): } \\
\text { Refutação/ Contraexpectativa } \\
\text { Ratificação / Confirmação de Expectativa }\end{array}$ \\
\hline & & & $\begin{array}{l}\text { Expansão Dialógica (38): } \\
\text { Acolhimento e Atribuição por Reconhecimento }\end{array}$ \\
\hline \multirow{2}{*}{$\begin{array}{l}\text { AR } \\
(35 \text { pareceres })\end{array}$} & \multirow[t]{2}{*}{$354(27 \%)$} & \multirow[t]{2}{*}{$944(73 \%)$} & $\begin{array}{l}\text { Contração Dialogica (381): } \\
\text { Refutação/ Contraexpectativa e Negação }\end{array}$ \\
\hline & & & $\begin{array}{l}\text { Expansão Dialógica (563): } \\
\text { Acolhimento }\end{array}$ \\
\hline \multirow{2}{*}{$\begin{array}{l}\mathrm{R} \\
(20 \text { pareceres })\end{array}$} & \multirow{2}{*}{$152(22 \%)$} & \multirow{2}{*}{$531(78 \%)$} & $\begin{array}{l}\text { Contração Dialógica (292): } \\
\text { Refutação/ Negação e Contraexpectativa }\end{array}$ \\
\hline & & & $\begin{array}{l}\text { Expansao Dialógica (239): } \\
\text { Acolhimento }\end{array}$ \\
\hline Total: 2.119 & $565(27 \%)$ & $1.554(73 \%)$ & \\
\hline
\end{tabular}

Quadro 3 - Demonstrativo dos posicionamentos nos pareceres

6. Por uma questão de espaço, serão apresentadas as categorias predominantes. No trabalho completo, apresentado na tese de doutorado, foram elencadas e exemplificadas todas as categorias presentes no corpus. 
A análise revelou menos ocorrências de posicionamentos monoglóssicos nos três grupos de pareceres, sendo $42 \%$ em A, 27\% em AR e $22 \%$ em R. É interessante observar que o grupo de pareceres A se diferenciou um pouco dos outros dois grupos de pareceres porque apresentou índice de monoglossia maior, apesar de não ter atingido a maioria de posicionamentos, considerando-se o total de ocorrências nesse grupo de pareceres. Esse dado pode revelar que, em se tratando de um grupo de pareceres com predomínio de avaliações positivas, as

Osilene Maria de Sá e Silva dacruz instanciações monoglóssicas podem evidenciar certeza do parecerista, o qual não considera importante dedicar espaço para posicionamento dialógico, ou seja, o estabelecimento das avaliações predominantemente positivas basta por si só, sem necessidade de propiciar dialogia. As ocorrências dialógicas ou heteroglóssicas, nos grupos de pareceres AR e $\mathrm{R}$, estão relacionadas à sugestão ou restrição do parecerista, podendo isso ser um indício de que o consultor não demonstra confronto com o articulista, mesmo quando se referia a problemas nos artigos.

Nas próximas subseções, apresento as particularidades dos posicionamentos em cada grupo de pareceres.

\subsection{Pareceres aprovados sem restrições}

Nesse grupo de pareceres, ocorre vantagem de posicionamentos heteroglóssicos, sendo a maioria com significados avaliativos positivos, podendo revelar que o parecerista proporciona ao interlocutor (articulista) oportunidade de interação. No entanto, o equilíbrio entre ocorrências de Contração Dialógica e Expansão Dialógica com uma leve vantagem para ocorrências de Contração Dialógica, realizadas principalmente por Contraexpectativa e Confirmação de Expectativa, pode ser um indício de que o parecerista aparenta dialogar com o interlocutor, mas restringe a possibilidade de dialogismo. Ocorrências de Expansão Dialógica são evidentes de duas formas: por Acolhimento, em enunciados em que a voz do parecerista é uma dentre outras vozes possíveis, e por Atribuição/Reconhecimento, em enunciados nos quais o parecerista coloca a reponsabilidade na voz do outro, como se estivesse um pouco mais distante do enunciado.

Apesar de os dados quantitativos indicarem predomínio de heteroglossia nesse grupo de pareceres, o que evidencia o reconhecimento de vozes alternativas por parte dos pareceristas, a análise mostra que essa dialogia pode estar camuflada, porque, se considerarmos o total de enun- 
ciados monoglóssicos (59), sem oportunidade de dialogia, com os índices de Contração Dialógica (41), em que ocorre restrição à voz dialógica, o total pode ser considerável (100), denotando uma estratégia do parecerista em aparentar sutileza e aceitação da voz do interlocutor, quando, na verdade, essa aceitação não é praticada efetivamente, promovendo, dessa forma, o desencorajamento do interlocutor para interagir.

Vale ressaltar que as ocorrências, de um modo geral, demonstram que a avaliação dos trabalhos é realizada de formas diferentes, a partir de escolhas linguísticas variadas, o que configura a variedade de opções dentro do campo linguístico de que o escritor/falante dispõe para se expressar. Como se pode ver, o diferencial é a opção do parecerista por um ou outro enunciado: monoglóssico ou heteroglóssico; de expansão ou de contração. É isso que definirá seu grau de envolvimento Contração ou expansão? posicionamentos em pareceres de revista científica sob a perspectiva sistemicofuncional com o interlocutor.

Seguindo a noção de dialogismo de Bakhtin, segundo a qual todo dizer está relacionado a outros dizeres e também antecipa outros dizeres, podemos ver a possibilidade de identificação de posicionamentos monoglóssicos no âmbito da oração; no entanto, no âmbito da semântica discursiva, essas ocorrências monoglóssicas apresentam-se mescladas com enunciados heteroglóssicos, como mostra o excerto do parecer A01.

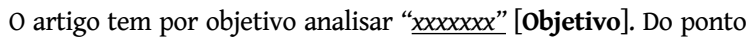
de vista teórico o(a) proponente baseia-se sobretudo na Teoria

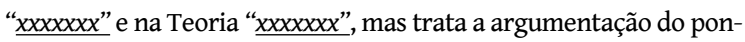

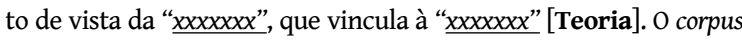
foi formado a partir das respostas de estudantes de um curso livre de espanhol, de um curso de extensão de uma universidade parti-

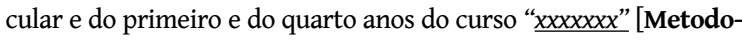

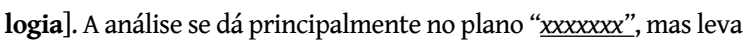
também em conta " $x x x x x x x "$ e " $x x x x x x x "$ [Análise].

Posto isto, pode se dizer que o artigo preenche as exigências da revista RL1. A contribuição mais relevante encontra-se na análise. (A01)

Nesse exemplo, o parecerista inicia o parecer com a contextualização da pesquisa, descrevendo os tópicos Objetivo, Teoria, Metodologia e Análise. Essa contextualização pode ser interpretada como uma escolha do parecerista para mostrar ao interlocutor 
Osilene Maria

de Sá e Silva

daCruz

seu domínio de conhecimento sobre o artigo analisado. Após essa contextualização, o parecerista manifesta a avaliação, por meio de um enunciado heteroglóssico de Confirmação de Expectativa ("Posto isto, pode se dizer que o artigo preenche as exigências da revista RL1"), como uma estratégia para fundamentar sua decisão baseada nas informações passadas anteriormente. A modalidade presente na expressão "pode-se dizer" pode indicar um recurso relativo à subjetividade do parecerista, como se proporcionasse ao interlocutor uma abertura dialógica.

As realizações heteroglóssicas indicam a intenção do parecerista em estabelecer diálogo com o interlocutor. Assim, por exemplo, o emprego do elemento conjuntivo "mas" ao se referir aos tópicos Teoria e Análise mostra uma restrição com relação à escolha teórica do articulista, que se baseia em duas teorias e ainda recorre a uma terceira teoria do ponto de vista da AD. Os itens lexicais "sobretudo" e "principalmente" são sinalizadores de intensificação do parecerista quando se refere aos tópicos Teoria e Análise, expressando intensidade (Gradação) no enunciado do parecerista, uma vez que instanciam sua intenção de intensificar o tipo de teoria empregada e o tipo de análise realizada.

O exemplo a seguir é um excerto do parecer A05 que também apresenta enunciados monoglóssicos e heteroglóssicos.

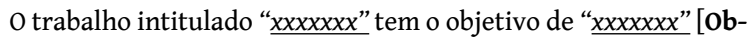

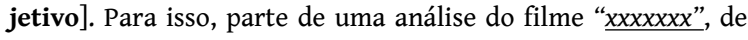

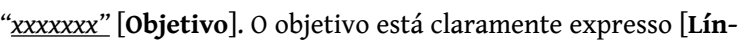
gua] e o autor constrói, de maneira consistente, sua argumentação [Argumentação].

Minha única sugestão seria que fosse feita mais uma revisão na forma do artigo, pois encontrei alguns erros na numeração e na bibliografia [Forma]. (A05)
}

Ao falar sobre os tópicos Objetivo, Língua e Argumentação, o parecerista recorre a alternativas monoglóssicas, mostrando ao leitor a certeza acerca do enunciado. Assim como no exemplo anterior, vemos a apresentação de sugestão de mudança após a apresentação dos referidos tópicos. Essa estratégia do parecerista pode revelar sua intenção em mostrar domínio de conhecimento sobre o que está sendo avaliado 
para, em seguida, apresentar sugestão de mudança, por meio de enunciados heteroglóssicos de Acolhimento ("minha única sugestão") e de Confirmação de Expectativa (“pois encontrei...").

Pode-se ver, também, nesse excerto que o parecerista reforça a avaliação positiva, com os elementos intensificadores "claramente" e "consistente". Ao apresentar a sugestão, por outro lado, recorre a quantificadores - "única" e "alguns" -, que parecem minimizar essa crítica negativa, podendo tornar a avaliação menos assertiva.

A seguir, apresento a discussão dos posicionamentos no grupo de Pareceres Aprovados com Restrições.

\subsection{Pareceres aprovados com restrições}

A análise revela maior interesse dos pareceristas em possibilitar interação com o interlocutor, devido ao considerável número de ocorrências heteroglóssicas (944), realizadas, sobretudo, por Expansão Dialógica (563), categoria Acolhimento, por meio da qual o autor/falante deixa transparecer sua subjetividade. As ocorrências monoglóssicas (354) ocorrem em menor escala e parecem indicar que o parecerista mostra ao interlocutor seu domínio sobre o artigo apresentado, revelando informações acerca de diferentes tópicos.

O parecer AR21 é um exemplo no qual ficam evidentes posicionamentos monoglóssicos e heteroglóssicos.

\footnotetext{
O autor do trabalho teve dois objetivos: discutir a questão ter-

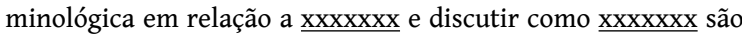
realizadas no texto em português brasileiro. Os dois objetivos são alcançados [Objetivo] mas o texto precisa ter uma outra organização para que a discussão seja mais clara [Forma]. Com relação ao primeiro objetivo, de modo geral, os conceitos estão misturados [Teoria]. No item 2, por exemplo, fala-se de $\underline{\operatorname{xxxxxxx}}$, da importância do $\underline{\operatorname{xxxxxxx}}$, da $\underline{\operatorname{xxxxxxx}}$ e do $\underline{\operatorname{xxxxxxx}}$ além de se fazer considerações sobre a terminologia [Teoria]. (AR 21)
}

Nesse exemplo, assim como ocorre com a marioria das ocorrências monoglóssicas desse grupo de pareceres, temos uma composição de enunciados monoglóssicos e heteroglóssicos. O parecer apresenta avaliação positiva sobre o tópico objetivo, realizada por monoglossia, re- 
Osilene Maria

de Sá e Silva

daCruz

velando o cumprimento do objetivo proposto. Em seguida, ocorre uma instanciação heteroglóssica, referente ao tópico Forma, pois o parecerista se posiciona restritivo quanto ao modo de apresentação do texto, usando o elemento conjuntivo "mas", sinalizando que essa apresentação pode comprometer sua clareza. No mesmo parágrafo, o parecerista aborda o tópico Teoria, recorrendo a instâncias heteroglóssicas, por meio de recurso de Reconhecimento da voz do articulista ("fala-se de

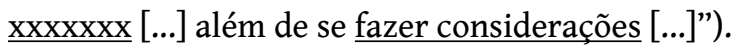

Ocorrências como essas, com evidências de enunciados monoglóssicos seguidos por heteroglóssicos e vice-versa, levam à reflexão de que a identificação e a classificação de asserções como monoglóssicas podem ser possíveis dentro do estrato léxico-gramatical; no entanto, levando-se em consideração o estrato semântico-discursivo, os enunciados constituem, em grande parte, heteroglossia.

A análise revelou também o predomínio de ocorrências monoglóssicas instanciadas com sentido de imperativo, por exemplo, por meio de verbos no infinitivo, podendo indicar a proposta do parecerista de forma enfática, ao demandar determinadas mudanças. Essas ocorrências não possibilitam interação ou voz alternativa do interlocutor, uma vez que sinalizam imposição, como mostra o exemplo do parecer AR02.

No resumo, acrescentar os pressupostos teóricos do trabalho.

Elaborar sobre 'xxxxxxx' para que o leitor tenha maiores referências do embasamento teórico que orienta o trabalho.

$\mathrm{Na}$ introdução (p. 1), e em outras partes do trabalho o termo

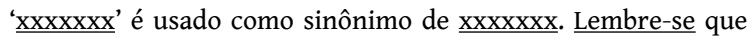
' $\underline{x x x x x x}$ ' refere-se a um conceito consideravelmente discutido na literatura, a que talvez, muito provavelmente "xxxxxxx" não corresponda.

Dar referência para a afirmação feita no primeiro período da Introdução. (AR02)

Nesse excerto, o parecerista se posiciona sem possibilitar interação com o interlocutor e faz isso por meio de propostas com sentido de comando pelos processos "acrescentar", “elaborar", “dar”, assim como pela ordem expressa "Lembre-se", de modo que não fica aberta a possibilidade de dialogia. Mesmo usando a realização monoglóssica, o pare- 
cerista mostra seu ponto de vista, o que se pode ver em "talvez, muito provavelmente", que, pelo tipo de significado, revela mais certeza do que incerteza.

A análise mostra que as realizações de Acolhimento foram feitas por posicionamento em primeira pessoa, denotando a intenção do parecerista em dialogar com o interlocutor; por ocorrências indicativas de probabilidade; por posicionamento do parecerista assumindo menos responsabilidade pelo que é dito; pela recorrência a elementos modais, sobretudo o modal "dever"; por perguntas abertas, como uma forma de esperar a resposta do articulista; pelo uso de metáfora interpessoal (HALLIDAY, 1994).

É importante destacar que o predomínio de ocorrências de Acolhimento pode revelar a intenção dos pareceristas em apresentar as propostas mantendo um continuum entre o "certo" e o "provável" e entre "sim" e "não", recorrendo a opções por verbos modais ("poder", "dever", "parecer", "ter", dentre outros) e apresentando as demandas de forma mais sutil, de maneira a ameaçar o mínimo possível a face do interlocutor. 0 exemplo a seguir mostra ocorrências da categoria Acolhimento nesse grupo de pareceres.

O trabalho é interessante e importante. Embora [Contraexpectativa] não tenha nenhuma objeção de conteúdo, penso [Acolhimento] que a utilização do palavra "xxxxxxx" deve ser repensada [Acolhimento] [...]. Por outro lado [Contraexpectativa], num texto que trata da adaptação de termos ingleses à língua portuguesa é no mínimo paradoxal aquilo que se escreve sobre a palavra "Xxxxxxx" e a sua utilização. Deveria ser tentada [Acolhimento] uma proposta de tradução/adaptação.

Na página 8, as explicações dos três tipos de recursos deveriam seguir [Acolhimento] o mesmo paradigma. [...]

$\mathrm{Na}$ página 12, quer-me parecer [Acolhimento] que o que

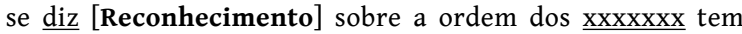

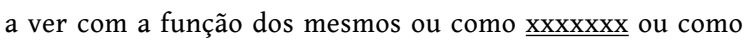
$\underline{\operatorname{xxxxxxx}}$, pelo que uma referência a tais funções talvez [Acolhimento] seja pertinente .

Para além destes aspectos, sugiro [Acolhimento], porém [Contra-Expectativa], que o/a autor/a faça uma revisão geral muito fina, pois [Conf. Expectativa] há vários ' $\underline{x x x x x x}$ ' ao longo do texto. (AR26) 
Osilene Maria

de Sá e Silva

daCruz
Nesse excerto é possível identificar várias propostas para correção do artigo, as quais são transmitidas permitindo-se o reconhecimento da subjetividade do parecerista. Em todos os enunciados de proposta, as realizações modalizadas ("deve ser repensada", "deveria ser tentada", “deveriam seguir", "talvez") ou em primeira pessoa ("penso", “quer-me parecer", "sugiro") parecem possibilitar abertura dialógica ao interlocutor. Apesar de realizações de ocorrências sinalizadoras de Contração Dialógica pelos elementos coesivos restritivos ("embora" e "porém"), neste excerto elas não conferem restrição interativa para os interlocutores.

Vale observar também no exemplo que, mesmo com alto índice de abertura dialógica, aparentando a possibilidade de aceitação de outras vozes e de negociação com o articulista, os recursos de Contração Dialógica/ Contraexpectativa ("embora", "por outro lado", “porém") podem evidenciar que essa aceitação parece limitada, tendo em vista a presença de enunciados denotativos de desacordo em relação ao que é apresentado pelo articulista. As ocorrências de Contraexpectativa evidenciam a autoridade do parecerista, uma vez que ele discorda, refuta e dificulta a interação com o interlocutor, assumindo maior responsabilidade pelo seu enunciado. Seguem ocorrências de Acolhimento.

(ix) Em 5.6 - a discussão se concentra nos participantes (reduzidos às categorias de "xxxxxxx" e "xxxxxxx" - ok, mas [Contraexpectativa] não [Negação] há definição destas categorias) - o que significam estes conceitos - neste trabalho? [Acolhimento]; além disto, não há distinção quanto à natureza destes participantes [Negação]: são eles as autoridades da saúde? [Acolhimento] Os produtores de cigarro? Os consumidores? [Acolhimento]. A contribuição do estudo seria maior [Acolhi-

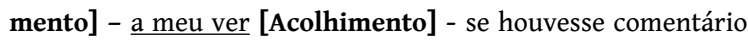

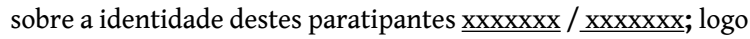
abaixo da tabela 11, há uma discussão de 2 ocorrências - a) e b) - que não [Negação] ficou clara para mim: por que 'xxxxxxx' é xxxxxxxe ‘xxxxxx'é xxxxxx? [Acolhimento] Talvez [Acolhimento] uma explicação detalhada aqui pudesse facilitar a tarefa de acompanhamento do argumento do texto. (AR15)

No excerto do parecer AR15, pode-se ver a avaliação do parecerista, ao apresentar aspectos negativos encontrados na análise do arti- 
go e restringir o diálogo por meio de Contraexpectativa ("mas") e por Negação, pela realização de modalidade negativa ("não há definição", "não há distinção", "não ficou clara"). Dessa forma, vê-se a responsabilidade total assumida pelo parecerista nesses enunciados, seguidos por enunciados de Expansão Dialógica: perguntas abertas ("o que significam estes conceitos - neste trabalho?”; "são eles as autoridades da saúde? Os produtores de cigarro? Os consumidores?"; “por que 'xxxxxxx' é

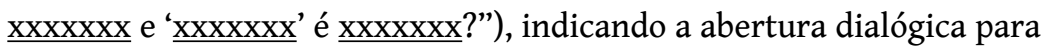
o articulista. Há também ocorrências de Acolhimento realizadas por posicionamento em primeira pessoa ("a meu ver") e por elemento modal de probabilidade ("talvez"). É importante destacar que esse conjunto de recorrências a categorias de Acolhimento pode revelar a tentativa do parecerista em manter solidariedade com o interlocutor, como um

Contração ou expansão? posicionamentos em pareceres de revista científica sob a perspectiva sistemicofuncional disfarce para que sejam aceitas suas restrições.

Ao optar por esses recursos, o parecerista se aproxima do interlocutor, utilizando um tom mais polido no seu posicionamento, mesmo em se tratando de propostas, por meio das quais ele apresenta suas demandas. Assim, a forma como essas demandas são expostas é mais sutil, pois são metaforizadas gramaticalmente.

Dando continuidade, a seguir, apresento os posicionamentos dos pareceristas no grupo de Pareceres Reprovados.

\subsection{Pareceres reprovados}

Os pareceristas optam, predominantemente, por escolhas heteroglóssicas (531), sendo a maioria com significados avaliativos negativos, e oferecem poucas oportunidades ao leitor de interagir. É possível ver também que, nos posicionamentos heteroglóssicos, ocorre o predomínio de Contração Dialógica, pelas categorias Refutação (Negação e Contraexpectativa). Esse dado pode indicar que, embora haja possibilidade dialógica, ela pode estar disfarçada, sinalizando, portanto, uma pseudodialogia. Realizações de Expansão Dialógica (239) foram realizadas predominantemente pela categoria Acolhimento, especificamente por meio de elementos modais, por posicionamento em primeira pessoa e por perguntas.

O quadro 3 mostra que o percentual de posicionamentos monoglóssicos (22\%) é inferior ao de posicionamentos heteroglóssicos (78\%). Ocorrências monoglóssicas, mesmo não sendo muito frequentes, podem revelar a estratégia de impedimento dialógico com o interlocutor. 
Osilene Maria

de Sá e Silva

daCruz

Por outro lado, os posicionamentos heteroglóssicos proporcionam uma abertura para a interação entre os participantes do discurso, invocando ou permitindo alternativas dialógicas, de expansão ou de contração (MARTIN; WHITE, 2005, p. 99-100).

O predomínio de ocorrências heteroglóssicas poderia ser um indício de abertura para vozes alternativas. No entanto, se for somado o total de ocorrências monoglóssicas (152), impeditivas de vozes alternativas, com as de Contração Dialógica (292), restritivas de vozes alternativas, chega-se um total considerável (444 ocorrências). Isso pode sinalizar que a abertura para dialogia não é tão clara quanto possa parecer, ou seja, os pareceristas restringem ou dificultam a presença de vozes alternativas. Dessa forma, pode-se inferir um posicionamento mais assertivo e de maior responsabilidade com relação às avaliações emitidas.

A análise dos posicionamentos monoglóssicos revelou também a utilização de processos de significado monoglóssico, sendo reveladores de avaliação negativa, por meio do elemento de polaridade negativa "não" ou por meio de elementos circunstanciais ("contrariamente"), sem intenção de demonstrar abertura para interação. Observam-se verbos flexionados em $1^{\mathrm{a}}$ pessoa, como "manifesto-me", "não recomendo", "sou de parecer desfavorável" e por verbos no infinitivo, no sentido semântico de imperativo, como "ver", "revisar", "refazer". Seguem alguns desses exemplos.

Como o trabalho se ressente de um maior rigor no uso da teoria mobilizada e como nele se enunciam conclusões - interessantes e relevantes sem dúvida - que excedem a análise feita, manifesto-me contrariamente à publicação do trabalho." (R01)

Em suma, o trabalho, apresenta problemas formais, conceituais e analíticos, e, mas, por tratar de pesquisa e temática relevantes, deve ser reescrito e reapresentado. Como está, não recomendo sua publicação. (R07)

Na tabela em que são apresentados os resultados da aplica-

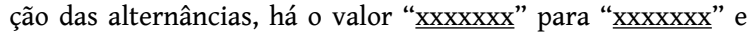
“xxxxxxx" para "Xxxxxxx" ou "xxxxxxx" (ver nota 3). (R09) 
Nos excertos dos pareceres R01 e R07, os pareceristas apresentam suas decisões tendo como base as razões citadas. No parecer R01, as razões do parecerista referem-se à teoria a que o articulista recorre e às conclusões aparentemente insuficientes, a partir da Análise apresentada. No parecer R07, o parecerista critica os problemas formais, conceituais e analíticos. Os processos "manifestar-se" e "recomendar", talvez, se empregados em outro contexto, fossem considerados heteroglóssicos, no entanto, nesse contexto, denotam a certeza dos pareceristas em apresentar a avaliação, uma vez que disporiam de outras opções no sistema linguístico. Optaram, porém, pelos processos que traduzem significados mais enfáticos, assertivos e incisivos no discurso. No excerto do parecer R09, o parecerista transmite sua proposta de forma incisiva ("ver"), sem possibilitar linguisticamente possibilidade de discussão

Contração ou expansão? posicionamentos em pareceres de revista científica sob a perspectiva sistemicofuncional com o articulista.

A análise revela que a maioria das ocorrências é realizada por Refutação, principalmente por realizações de modalidade negativa, características de Negação, podendo ser um indício de restrição com relação a vozes alternativas e revelando ao interlocutor uma posição ou ponto de vista com o qual ele não concorda, pois sua posição é contrária à apresentada no artigo. Segundo Martin e White (2005), ocorrências de Refutação mostram a responsabilidade máxima que o falante ou escritor impõe no enunciado. O exemplo a seguir, extraído do parecer R02, será discutido a seguir.

1. Embora o trabalho aborde uma questão interessante [Contraexpectativa], o objetivo do trabalho não está claramente expresso [Negação], não havendo também uma articulação bem construída entre as seções [Negação].

2. Observações sobre a argumentação:

A argumentação não está bem desenvolvida [Negação] e, portanto [Confirmação de expectativa], não é convincente [Negação]. Já no início do texto, não há um estabelecimento claro do problema [Negação]. O autor coloca, na primeira sentença [Reconhecimento]:

'Essa proposta é uma tentativa de estabelecer, com um pouco mais de precisão, a diferença entre "Xxxxxxx" e "xxxxxxx".

e mais abaixo: 
Osilene Maria

de Sá e Silva

daCruz
Mas tenho a intenção de mostrar que "xxxxxxx" são estabelecidos em uma " $\underline{\operatorname{xxxxxx}}$ ", e, que, sintaticamente, a diferença entre “xxxxxxx" e "xxxxxxx" é simplesmente estrutural, ou seja, é só uma questão de posição e que não tem relação com "xxxxxxx". Assim, não fica claro se o texto vai estabelecer as diferenças entre "xxxxxxx" e "xxxxxxx" [Negação], ou se vai argumentar a favor de um mapeamento não estrito entre "xxxxxxx" e realização estrutural. (R02)

Esse excerto é constituíido por avaliações sobre diversos tópicos, tais como Tema, Língua, Forma e Argumentação, as quais são reveladas, sobretudo, por orações com polaridade negativa, características da categoria Negação. No entanto, o parecerista utiliza estratégias para disfarçar esse posicionamento de extrema responsabilidade ao avaliar, como pode ser visto no início do parecer, quando ocorre a única avaliação positiva relativa ao Tema do artigo, considerado interessante. A partir desse elogio, o parecerista destaca vários problemas relacionados à falta de clareza com relação ao tópico Objetivo, à falta de articulação entre as seções, afetando o tópico Forma.

Além disso, utiliza enunciados de polaridade negativa para avaliar o tópico Argumentação, que não está bem desenvolvido e não é convincente. A falta de clareza ocorre também no estabelecimento do problema tratado no artigo. Trata-se de um excerto constituído, na sua maioria, por posicionamentos de Contração Dialógica (Contraexpectativa e Negação), exceto uma ocorrência de Expansão Dialógica (Reconhecimento), na qual o parecerista reconhece a voz do autor, reproduzindo suas próprias palavras no artigo.

Nota-se que o parecerista recorre à voz do articulista como uma estratégia de busca de solidariedade quanto à avaliação negativa, uma vez que essa citação é utilizada para fundamentar a avaliação. É importante destacar, também, a importância dedicada pelo parecerista aos aspectos relativos ao tópico Língua, especificamente no que se refere à clareza na apresentação do objetivo, do problema a ser tratado e dos argumentos no artigo.

Os dados mostram o predomínio de ocorrência de Expansão Dialógica (239) realizado, sobretudo, por recursos da categoria Acolhi- 
mento, por meio de elementos modais, posicionamento em primeira e terceira pessoa, perguntas e modalização, deixando transparecer subjetividade, admitindo e reconhecendo vozes alternativas. Essas ocorrências podem tornar a avaliação mais polida, menos hostil ao interlocutor, amenizando o posicionamento do parecerista e tornando-se mais acessível à solidariedade externa. As realizações de Acolhimento são concretizadas em proposições e propostas, revelando o que deve ser feito para que o trabalho assuma o nível de qualidade exigido no meio acadêmico. Vejam-se os exemplos a seguir.

$\mathrm{Na}$ análise, algumas "xxxxxxx" parecem ser [Acolhimento] categorizadas equivocadamente principalmente as classificadas como "Xxxxxxx", que, na maioria das vezes parecem ser, [Aco-

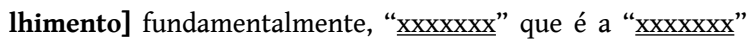
mais importante "xxxxxxx"). Como muitas dessas classificações têm um caráter subjetivo, elas podem até ser aceitas [Acolhimento], mas [Contraexpectativa] devem ser mais bem justificadas [Acolhimento]. Um exemplo seria [Acolhimento] a expressão "xxxxxxx” “"xxxxxxx”, que é classificada como “xxxxxxx”, além de outras como “" $\underline{x x x x x x ”}$ ”. Outras classificações que podem gerar [Acolhimento] estranhamento seriam [Acolhimento]: “"xxxxxx”” (“Xxxxxxx” não [Negação] é sempre resultado da experiência "xxxxxx") e “"xxxxxxx" é um “xxxxxxx"'. A análise poderia ser beneficiada [Acolhimento]

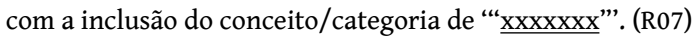

Esse excerto mostra o posicionamento do parecerista de forma consideravelmente dialógica, por meio da qual ele critica o tópico Análise, considerando problemas na categorização de "xxxxxxx" no trabalho. Esse posicionamento é evidenciado principalmente por enunciados modalizados, revelando pouco comprometimento com a avaliação, pois esta é apresentada de forma sutil ("parecem ser", "podem gerar", “seria”, "seriam", “podem até ser aceitas", “poderia ser"). Apesar do uso recorrente de elementos modalizadores, sinalizando abertura para vozes alternativas, enunciados realizados por Contração Dialógica - Contraexpectativa ("mas") e Negação ("não") -, parecem restringir essa abertura ao diálogo, disfarçando o Acolhimento, pois o parecerista 
Osilene Maria

de Sá e Silva

dacruz

mostra sua ênfase ao restringir ("mas devem ser") e ao apresentar Negação ("não é sempre"). Nesse exemplo, portanto, pode-se ver o uso de possibilidade de vozes alternativas, porém, não em sua totalidade, uma vez que são apresentadas propostas de mudança.

De acordo com Brown e Levinson (1987), estratégias como essas de polidez demonstram a intenção do autor/falante em preservar sua face, de forma que as demandas sejam apresentadas em forma de sugestão. Halliday (1994) também menciona estratégias realizadas por meio de metáforas interpessoais, uma vez que, ao utilizarem proposições e propostas, tornam evidente que algo é informado, pedido e desejado, sendo apresentados de forma sutil, substituindo outra possível escolha, como, por exemplo, "É dito que" ou "Faça isso ou aquilo".

Apresentadas as análises e discussões sobre os posicionamentos dos pareceristas, seguem as considerações finais deste artigo.

\section{Considerações finais}

Esta pesquisa analisou o posicionamento de pareceristas ao avaliarem artigos submetidos a uma revista científica da Linguística e baseou-se no arcabouço teórico-metodológico da Linguística Sistêmico-Funcional e do Sistema de Avaliatividade. No âmbito da LSF, a pesquisa possibilitou identificar aspectos da avaliação atitudinal, principalmente, no que se refere às relações entre os participantes da interação, especialmente, parecerista e articulista. Por meio da análise da metafunção interpessoal e do subsistema Engajamento, verificou-se como as críticas e as propostas são apresentadas aos articulistas.

Embora estudos sobre Avaliatividade tenham se multiplicado no contexto acadêmico brasileiro nos últimos anos, sinto necessidade de ampliar essas referências, como uma forma de mostrar a adequação da teoria para a língua portuguesa.

Com relação às contribuições deste trabalho, destaco a possibilidade de analisar o gênero parecer, uma vez que se evidencia uma lacuna de estudos sobre esse gênero, contribuindo para o estudo da escrita acadêmica uma vez que, embora sejam recorrentes pesquisas sobre escrita acadêmica (resenha, resumo, teses, dissertações, monografias, etc), o presente estudo pode se configurar como uma fonte adicional para pesquisadores interessados no gênero que a escrita configura. Soma-se a isso o fato de que a pesquisa pode oferecer a escritores, de modo geral, experientes e novatos, informações relativas ao que é considerado 
mais importante em um artigo científico. Os resultados podem revelar os tópicos mais avaliados e abordados pelos pareceristas, mostrando, consequentemente, o que é relevante ser considerado pelos articulistas ao desenvolverem seus próprios artigos, tendo como base as avaliações de pareceristas de uma revista conceituada (RL1).

Com relação às limitações deste estudo, destaco a impossibilidde de apresentar uma análise mais detalhada, rica em exemplos e comentários, que poderia contribuir significativemante para outros estudiosos (novatos ou experientes) na análise de textos acadêmicos e nas interações presentes nos discursos. Outra limitação refere-se à impossibilidade de apresentar, neste artigo, instanciações relativas aos subsistemas Atitude e Gradação, também reveladores de dados importantes sobre os avaliação nos pareceres. Sugiro, então, a leitura da tese completa, para

Contração ou expansão? posicionamentos em pareceres de revista científica sob a perspectiva sistemicofuncional

\section{Referências}

ALMEIDA, F. S. D. P. A avaliação na linguagem: os elementos de Atitude no discurso do professor: um exercício em análise do discurso sistêmico-funcional. São Paulo: Pedro \& João Editores, 2010.

BAKHTIN, M. Marxismo e filosofia da linguagem. [1929]. Tradução: Michel Lahud e Yara Frateschi Vieira. 9.ed. São Paulo: Hucitec, 1999.

BAZERMAN, C. Systems of genres and the enactement of docial intentions. In: FREEDMAN, A.; MEDWAY, P. Genre and the New Rhetoric. London: Taylor \& Francis. 1994. p. 79-101.

. Gênero, agência e escrita. Tradução: Judith Chambliss Hoffnagel. São Paulo: Cortez, 2006.

BESERRA, N. da S. Parecer, pareceres: como um gênero pode regular a vida das pessoas. In: PG LETRAS 30 ANOS - O CAMINHO SE FAZ CAMINHANDO. 2006, Anais... Pernambuco: UFPE, 2006, p. 481-494. 1 CD-ROOM. 
BROWN, P.; LEVINSON, S. Politeness: some universals in language usage. Cambridge: Cambridge University Press, 1987.

CABRAL, S. R. S. A mídia e o presidente: um julgamento com base na Teoria da Valoração. 2007. 241 f. Tese (Doutorado em Letras) Universidade Federal de Santa Maria, Santa Maria, RS, 2007.

CARVALHO, G. A prosódia atitudinal: Apreciação e Julgamento em

Osilene Maria

de Sá e Silva

daCruz críticas de cinema. In: VIAN JR, O; SOUZA, A. A.; ALMEIDA, F. S. D. P. (Orgs). A linguagem da avaliação em língua portuguesa: estudos sistêmico-funcionais com base no Sistema de Avaliatividade. São Paulo: Pedro \& João Editores, 2011. p. 113 - 129.

CHIZZOTTI, A. Pesquisa em Ciências Humanas e Sociais. 3.ed. São Paulo: Cortez, 1998.

CRUZ, O. M. S. S. A Avaliatividade em pareceres de revista científica de Linguística: uma perspectiva sistêmico-funcional. 2012. 220p. Tese (Doutorado em Linguística Aplicada e Estudos da Linguagem). Pontifícia Universidade Católica de São Paulo, São Paulo, 2012

DENZIN, N.; LINCOLN, Y. Entering the field of qualitative research. In: DENZIN, N.; LINCOLN, Y. (Eds.) Collecting and interpreting qualitative materials. Thousand Oaks: Sage Publications, 1998. p. 1-34.

DUFF, P. A. The Oxford Handbook of Applied Linguistics. Oxford: Oxford University Press, 2002.

FLICK, U. Introdução à pesquisa qualitativa. Tradução: Joice Elias da Costa. 3.ed. São Paulo: Artmed, 2009.

HALLIDAY, M. A. K. An introduction to Functional Grammar. London: Edward Arnold, 1985.

. An introduction to Functional Grammar. 2.ed. London: Edward Arnold, 1994.

HALLIDAY, M. K. A.; MATTHiESSEN, C. M. I. M. An introduction 
to Functional Grammar. 3.ed. London: Hodder Education, 2004.

HOUAISS, A.; VILLAR, M. S. Dicionário Houaiss da língua portuguesa. Rio de Janeiro: Objetiva, 2001.

IKEDA, S. N. O Julgamento na argumentação de um editorial. In: VIAN JR, O. et al (Orgs.). A linguagem da avaliação em língua portuguesa. São Paulo: Pedro \& João Editores, 2011. p 167-188.

MARTIN, J. R.; WHITE, P. R. R. The language of evaluation - appraisal in English. Great Britain: Palgrave Macmillan, 2005.

MILLER, C. R. Rhetorical community: the cultural basis of genre. In: FREEDMAN, A.; MEDWAY, P. (Eds.). Genre and the New Rhetoric. London/Bristol: Taylor \& Francis, 1994. p. 67-78.

MOITA LOPES, L. P. Oficina de Linguísitica Aplicada. Campinas: Mercado das Letras, 2001.

PAULA, S. M. O metadiscurso em introduções de artigos científicos: uma perspectiva sistêmico-funcional. 2009. 81fls. Dissertação (Mestrado em Linguística Aplicada e Estudos da Linguagem) - Pontifícia Universidade Católica de São Paulo, São Paulo, 2009.

RAMOS-ÁLVAREZ et al. Criteria of the peer review process for publication of experimental and quasi-experimental research in Psychology: A guide for creating research papers. International Journal of Clinical and Health Psychology. Espanha, v. 8. n. 3, p. 751-764, 2008.

RODRIGUES JR., A. S. Ideação e Avaliatividade em relatos de aprendizes de inglês como língua estrangeira. Revista Brasileira de Linguística Aplicada. Belo Horizonte, v. 8, n. 2, p. 273 - 293, 2008.

SOBHIE, M. T. B. O Engajamento em um artigo de opinião sobre as novas tecnologias. In: VIAN JR, O. et al. (Orgs.). A linguagem da avaliação em língua portuguesa. São Paulo, Pedro \& João Editores, 2011. p. 79-96.
Contração ou expansão?

posicionamentos em pareceres de revista científica sob a perspectiva sistemicofuncional 
THOMPSON, G. Introducing Funcional Grammar. London: Edward Arnold, 1996.

VIAN JR., O. O Sistema de Avaliatividade e os recursos para Gradação em língua portuguesa: questões terminológicas e de instanciação. D.E.L.T.A. São Paulo, v. 25, n. 1, p. 99-129, 2009.

\section{Osilene Maria de Sá e Silva daCruz}

